\title{
Mapping rangeland ecosystems vulnerability to Lantana camara invasion in semi-arid savannahs in South Africa
}

\author{
Timothy Dube $^{1} \odot \mid$ Xivutiso Glenny Maluleke ${ }^{2} \odot \mid$ Onisimo Mutanga ${ }^{2}$
}

${ }^{1}$ Institute of Water Studies, Department of Earth Sciences, The University of the Western Cape, Bellville, South Africa

${ }^{2}$ Geography \& Environmental Science, School of Agric. Earth \& Environmental Sciences, University of KwaZulu Natal,

Pietermaritzburg, South Africa

\section{Correspondence}

Timothy Dube, Institute of Water Studies, Department of Earth Sciences, The University of the Western Cape, Private Bag X17, Bellville 7535, South Africa.

Email: tidube@uwc.ac.za

\begin{abstract}
We mapped and modelled the potential areas vulnerable to Lantana camara (L. camara) invasion in semi-arid savannah ecosystems in the communal lands of Bushbuckridge and Kruger National Park, South Africa. Specifically, we modelled potentially vulnerable areas based on remotely sensed data and environmental variables. The Maximal Entropy (Maxent) algorithm was used to model the vulnerable area. The reliability of the modelled results was assessed using Skills Statistic (TSS), Area Under Curve (AUC) and Kappa statistics. According to the results, Bushbuckridge communal lands are more susceptible to L. camara invasions than Kruger National Park. The risk of L. camara invasion in the study site was modelled with high accuracy (AUC score of 0.95) using the best model (Model 7), which is a composite of all model variables (remote sensing and environmental variables). The spatial distribution maps derived from Maxent showed that L. camara was more likely to invade communal lands than protected areas. Using remotely sensed spectral indices as standalone model variables (Model 4) showed the lowest accuracy, with an AUC score of 0.85 . Overall, model input variables such as elevation had a significant influence on the spatial distribution of L. camara in the study area.
\end{abstract}

\section{KEYWORDS}

environmental variables, invasive plants encroachment, L. camara, Maxent, rangeland ecosystems, semi-arid environments

\section{Résumé}

Nous avons cartographié et modélisé les zones potentielles vulnérables à l'invasion des écosystèmes de savane semi-arides situés dans les terres communales de Bushbuckridge et du parc national de Kruger, en Afrique du Sud, par l'espèce Lantana camara (L. camara). Plus précisément, nous avons modélisé des zones potentiellement vulnérables à partir de données de télédétection et de variables environnementales. L'algorithme Maximal Entropy (Maxent) a été utilisé pour modéliser la zone vulnérable. La fiabilité des résultats modélisés a été évaluée à l'aide des méthodes TSS, de l'aire sous une courbe (ASC) et du Kappa. Selon les résultats, les terres communales de Bushbuckridge sont plus vulnérables aux invasions par l'espèce $L$. camara que le parc national Kruger. Le risque d'invasion par l'espèce L. camara sur le site d'étude a été modélisé avec une grande précision (score ASC de 0,95) à l'aide du meilleur modèle (modèle 7), qui est un composite de toutes les variables du modèle (télédétection 
et variables environnementales). Les cartes de répartition spatiale dérivées de l'algorithme Maxent ont montré que l'espèce L. camara était plus susceptible d'envahir les terres communales que les aires protégées. L'utilisation d'indices spectraux de télédétection comme variables de modèle autonomes (modèle 4) a présenté le niveau de précision le plus faible, avec un score d'ASC de 0,85. Dans l'ensemble, les variables relatives aux entrées du modèle, comme l'altitude, ont eu une influence significative sur la répartition spatiale de l'espèce L. camara au sein de la zone d'étude.

\section{1 | INTRODUCTION}

Non-native species are important agents of global ecological change. After anthropogenic environmental damage and natural ecosystem destruction, these species are perceived as a threat to biodiversity (Gooden et al., 2009). Plant invaders, also known as environmental weeds, change ecosystem structure due to their impact on native vegetation density and distribution (Mack et al., 2000). Globally, L. camara is one of the most prevalent invasive alien plant (IAP) species and has become a major invader of agricultural areas and natural ecosystems (Dobhal et al., 2011). Once established, the species is extremely difficult to manage, contain and eradicate and poses a serious threat to savannah rangelands. Thus, preventing its introduction or rehabilitating the affected areas may be the most cost-effective management method (Gallien et al., 2012).

Lantana camara was introduced as an ornamental plant in various countries, globally. Since then, it has become invasive in most countries including South Africa; it has been ranked by the invasive species specialist group (IUCN 2001) one of the world's top invasive species (Sharma et al., 2005). The invasion by L. camara associated with the reduction in grazing pastures, invertebrate diversity (Vardien et al., 2012). In South Africa alone, L. camara had invaded about two million hectares in the year 2000. Its invasion has been associated with increasing thickets, which obstruct pathways to sources of water, and reducing the quality of water within various river catchments such as Hartenbos and Klein Brak (Taylor \& Kumar, 2014). A good example is Bushbuckridge, which is an area located at the edge of the Kruger National Park in South Africa, where most of the land is reserved for wildlife and livestock grazing. The intrusion of L. camara in this area has resulted in increased replacement of natural ecosystems such as grasslands, which are vital for the provision of forage for livestock and wildlife (Masocha et al., 2017).

Interestingly, the distribution of the L. camara species differs, depending on the biotic and abiotic conditions (West et al., 2016). These variations affect the plant species in various ways as they limit, disturb or provide conducive conditions for these plant species (Guisan \& Thuiller, 2005). Environmental variables such as topography and climate affect the spatial distribution of invasive alien plants (Guisan \& Thuiller, 2005). For example, topographic variables such as slope, elevation and aspect influence microclimatic conditions, which later regulate the amount and quality of soil nutrients and light availability (Wang et al., 2017). In addition, rainfall and temperature have a significant effect on the establishment and dispersal of the IAP's species (Zhu et al., 2007). The relationship between the species and their overall environment can result in variations in their distribution, a common characteristic across various landscape scales (Pearson et al., 2004). Thus, for the estimation of the potential niche of the IAP's species and their spatial distribution, it is important to establish precise environmental factors limiting its distribution as well as those that favour its growth. However, such detailed information is lacking for most species (Priyanka \& Joshi, 2013a,b). As such, the inclusion of environmental factors in understanding the occurrence and the spatial distribution of L. camara can enhance management of these species, particularly in semi-arid savannah ecosystems.

To date, two broad approaches, namely field traditional-based methods and remote sensing (RS) techniques, are used to quantify alien invasive species. Although traditional methods based on visual interpretations and field surveys are highly accurate, they are often difficult to conduct across large regions, besides time-consuming, expensive and labour-intensive (Odindi et al., 2014; Taylor et al., 2011; Thamaga \& Dube, 2018a,b). In contrast, the RS technique offers the ability to acquire valuable and relatively cheap primary data that are necessary for timely and accurate quantification of different species (Thamaga \& Dube, 2018a,b). Additionally, RS has successfully overcome the challenges associated with conventional approaches, such as time, cost and the accessibility of large geographic unit (Dube et al., 2018). The increasing number of sensors has provided scientific researchers with spatial data, creating opportunities to map and model the distribution of these invasive species.

The utility of RS technologies in mapping invasive species has gained increasing attention globally (Dube et al., 2016; Dube \& Mutanga, 2015). Over the years, numerous satellite datasets have been successfully used in mapping and modelling L. camara, with different degrees of accuracy. For instance, Dhau (2008) utilized Landsat TM and Aster datasets in mapping and monitoring the invasion of L. camara across three different land tenure systems in Zimbabwe. Kimothi and Dasari (2010) also explored the Indian satellite data in mapping the spatial distribution of the intrusive L. camara in forest landscapes. The study demonstrated the ability of Linear Imaging Self-Scanning Sensor (LISS) IV and Cartosat-1 data for the detection and mapping of L. camara. However, there has been a paradigm shift in satellite remote sensing because of their limitations and the need for continuous improvement in mapping (DeFries et al., 2004). The application of medium spatial resolution in L. camara modelling has 
been limited by the insufficient spatial and spectral capabilities (Xie et al., 2008). The application of moderate spatial resolution sensors such as the Landsat $8 \mathrm{OLI}$, Landsat 7 ETM+ and SPOT- 5 has been restricted when dealing with the world's worst understory plant species such as L. camara, mainly because they are unable to detect species occurrence in small and isolated patches (Zhang \& Foody, 1998). For example, Mullerova et al. (2013) tested the effects of image classification with different spatial resolutions in the detection of invasive Heracleum mantegazzianum (Giant hogweed). Between the two tested satellite datasets, the results revealed that the high spatial resolution VHR performed better than the Rapid Eye.

According to Huang and Gregory, (2009), the use of moderate spatial resolution images in mapping and monitoring of IAPs is not yet fully understood in a background of native vegetation and it is therefore challenging, in terms of detection and mapping. Huang and Gregory (2009) further noted that these data could only be used to detect large patches of weeds that rely more on the phonological time. For instance, a study done by Fernando et al. (2016) produced low accuracies in mapping L. camara at species level, using the $30 \mathrm{~m}$ Landsat TM and SPOT data with moderate spatial resolutions. Nonetheless, the spatial, spectral and temporal characteristics of Sentinel-2 provide unique opportunities (Addabbo et al., 2016). Sentinel-2 is a high spatial resolution (10-60 m) sensor with a temporal resolution of five days, which is usually higher due to its image acquisition angle adjustment capability, hence making the sensor a key tool for large-scale mapping, especially in resource scares zones (Sibanda et al., 2015). It is also the first optical sensor to have the rededge bands, which is known to increase the sensitivity of vegetation and its spectral response. The use of satellite data with a wider width and unique spectral characteristics such as those of Sentinel-2 may improve the detection and prediction of the geographic distribution of L. camara. The integration of RS data in Species Distribution Models (SDMs) has improved the estimation of the likelihood of species occurrence in areas (Kozak et al., 2008; Rocchini et al., 2015). The spectral reflectance characteristics provided by RS offer SDMs species information that is distinct, supporting models to distinguish between suitable and unsuitable areas that cannot be distinguished solely from topographic and bioclimatic factors (Gallien et al., 2012).

SDMs have been introduced as tools that can aid in understanding and predicting current and future species invasion. SDMs are a fixed portrayal of habitats that are suitable for species distribution (Bateman et al., 2012). They are mainly based on the correlation between the occurrence of species and ecological features, whereby their functionality is built on the establishment of relations between a species identified range and selected environmental variables. Thereafter, the relationship is used to detect other areas that may be inhabited by the species of interest (Beaumont et al., 2008). The spatial distribution of IAPs species has previously been modelled using different SDMs. The majority of SDMs use presence and absence data. However, there has been a limitation concerning acquiring absence data (Phillips et al., 2006). Hernandez et al. (2006) noted that the Maximum entropy (Maxent) model was the best modelling method when compared to Multivariate distance (DOMAIN), GARP and Envelope model
(BIOCLIM). It was anticipated that Domain, GARP and Bioclim performed poorly due to the small sample sizes. In a study by Wisz et al. (2008), it was found that Boosted decision trees (GBM) and multivariate adaptive regression splines (MARS) which are a rapid application of a Generalized Additive Models (GAM: BRUTO) performed exceptionally well and superior to other techniques, especially when dealing with a larger sample size. The Rule and DOMAIN sets determined by genetic algorithms as well as open modeller version (OM-GARP) were some of the foremost performers when considering smaller sample sizes. However, they produce average results with bigger sample sizes. Additionally, the Maxent entropy was found to be less sensitive to different sample sizes and was the best model to predict species distribution with the use of both large and small sample size.

The Maxent entropy model is an SDM with great potential for identifying invasive species distribution. It is a correlative approach that has been identified among the best SDM for present-only data analysis (Ficetola et al., 2007). This method requires present-only data and a low number of locations to construct models. It has a higher performance when compared to other present-only models, due to its sensitivity to spatial errors that are related to low data (Phillips et al., 2006). Furthermore, it allows the usage of both continuous and categorical variables. Its regularization procedure makes it prone to overfitting as it compensates for small occurrence data (Merow et al., 2017; Phillips et al., 2006).

However, there has been considerable level of success documented in modelling the spatial spread of L. camara. However, there are still shortcomings in understanding the factors affecting its versatility of invasions that occur in new environments. As such, mapping of L. camara alone is not enough, as it does not explain why the species is occurring in those regions; hence, there is need to incorporate environmental variables in the RS of L. camara in Savannah rangelands. This study thus sought to determine the influence of environmental variables in the spatial variability of $L$. camara in savannah ecosystems, utilizing the Maxent algorithm in concert with remotely sensed data derived from the Sentinel-2 satellite data.

\section{2 | MATERIALS AND METHODS}

\subsection{Study area}

This research was carried out in the communal area of Bushbuckridge and Kruger National Park (Figure 1). Bushbuckridge is located between the Drakensberg escarpment and the Kruger National Park, which is close to the Sabie-Sand Game. Rainfall is approximately $1200 \mathrm{~mm}$ per annum in the western region to $500 \mathrm{~mm}$ in the eastern region, while the average yearly temperature is roughly $22^{\circ} \mathrm{C}$. The terrain is characterized by flat to undulant surfaces. The thin sandy lithosol is the dominant soil type in the area with low-lying areas having different soil types. The standard vegetation is mainly the open extensive grasslands and deciduous forests. The utmost livestock found in the area is domesticated animals, such as cattle and goats, while the agricultural activities include crop planting. The 


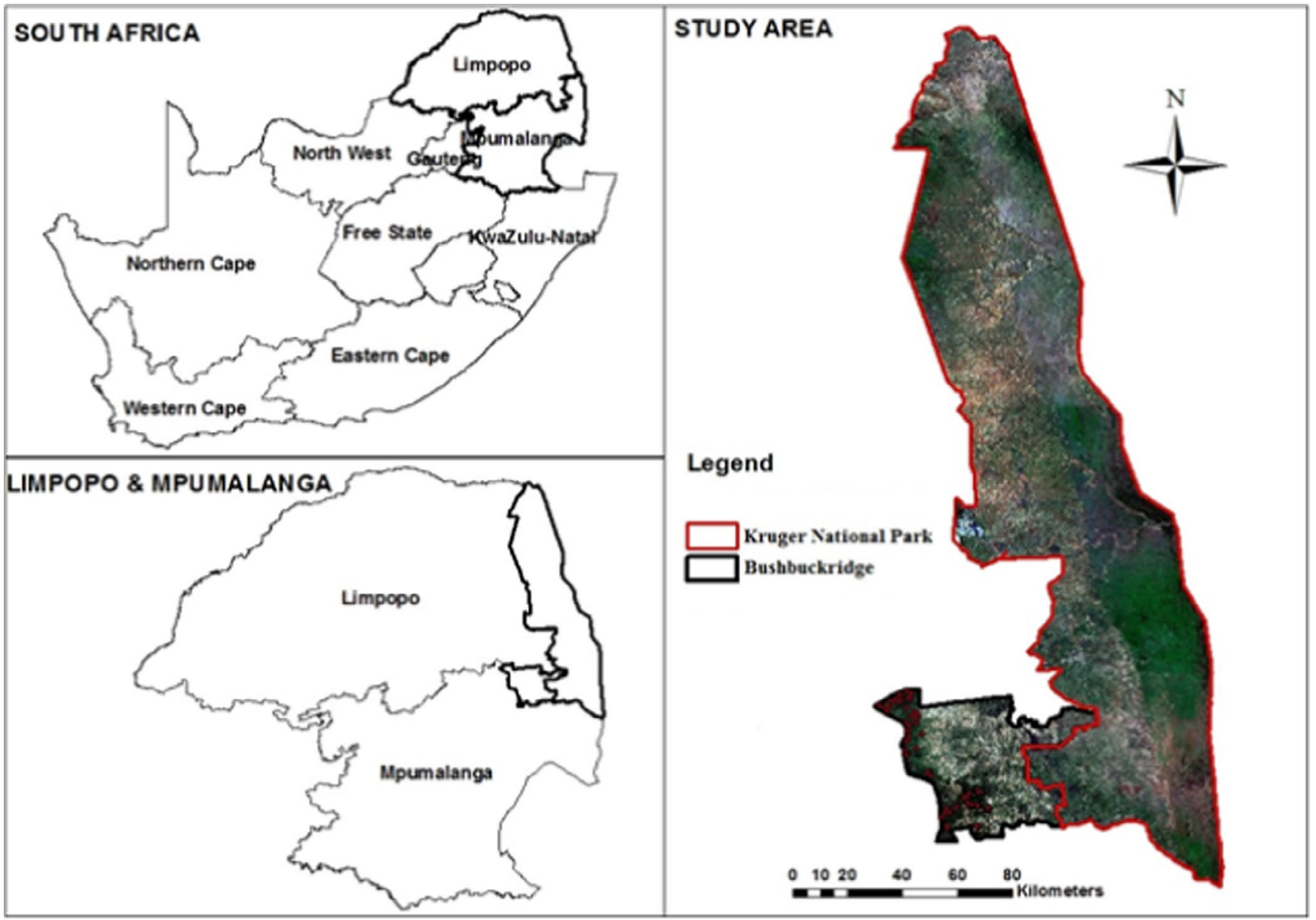

FIGURE 1 Location map of the study area

Kruger National Park is one of the largest in the world $\left(19,485 \mathrm{~km}^{2}\right)$ and is located along the eastern part of Mpumalanga and Limpopo provinces in South Africa. It is about 65 and $360 \mathrm{~km}$ in width and length, respectively. The region is characterized by subtropical climate type with hot and humid summer days. Rainy season begins around September all through to the month of May.

\subsection{1 | Field data collection}

Field data were collected in July 2017, following a systematic sampling procedure. Stratified random transects were generated in a GIS environment. The generated points were then uploaded on a Trimble Juno $3 B$, hand-held GPS. Subsequently the points were used to locate the sampling sites on the field. Specifically, a quadrant within the 30-40 transect after every 10-m interval was used. Eighty sample points were generated using field data and then divided into $70 \%$ for model training and $30 \%$ for model validation. The GPS captured coordinates were presented in a table format using Microsoft Excel Version 4.0. The GPS was then imported into a GIS environment and overlaid on the study area GIS layer. For purposes of compatibility with Maxent, the measured the L. camara GPS points were changed to comma-separated values (csv) and used for the modelling of potential vulnerable areas.

\section{2 | Image acquisition and processing}

The freely accessible Sentinel-2 imagery was used in this study. A cloudless satellite dataset of Sentinel-2 covering the study area was downloaded from Sentinel Copernicus data hub. The acquired images coincided with field data collection. Sentinel-2 is a multispectral sensor that was launched on the 23 June 2015. It comprises of two indistinguishable satellites, namely Sentinel-2A and Sentinel-2B. The satellite is characterized by a high temporal resolution with fiveday return intervals. The satellite collects data at $10 \mathrm{~m}$ (blue, green, red and near infrared 1 ) and $20 \mathrm{~m}$ (red edge1 to 3, close infrared-2, short waves infrared 1 and 2), respectively. For this study, bands 1, 9 and 10 were excluded due to the course spatial resolution of $60 \mathrm{~m}$. Atmospheric correction of the acquired images was carried out with the aid of a toolbox called Sen2cor within the Sentinel Application Platform (SNAP) tool Version 4.0.

\section{3 | Topographic indices}

To model the occurrence and distribution of L. camara, the 30-m digital elevation model (DEM) from the Advanced Spaceborne Thermal Emission and Reflection Radiometer (ASTER) was used. Specifically, 
TABLE 1 Model scenarios with selected environmental inputs

\begin{tabular}{|c|c|c|}
\hline Model scenario & Variables & $\begin{array}{l}\text { No. of } \\
\text { variables }\end{array}$ \\
\hline Model 1 & Aspect, elevation, slope, TPI, TWI & 5 \\
\hline Model 2 & Bands $2,3,4,5,6,7,8,8 a, 11,12$ & 10 \\
\hline Model 3 & Bios 01, 02, 05, 06, 07, 12, 13, 14, 17 & 9 \\
\hline Model 4 & GNDVI, NDVI, RVI, TVI & 4 \\
\hline Model 5 & $\begin{array}{l}\text { Aspect, elevation, slope, TPI, TWI, bands } 2,3,4,5,6,7 \text {, } \\
\quad 8,8 a, 11,12\end{array}$ & 15 \\
\hline Model 6 & $\begin{array}{l}\text { Aspect, elevation, slope, TPI, TWI, bios 01, 02, 05, 06, } \\
07,12,13,14,17\end{array}$ & 15 \\
\hline Model 7 & $\begin{array}{l}\text { Aspect, elevation, slope, TPI, TWI, Bands 2, 3, 4, 5, 6, 7, } \\
\text { 8, 8a, 11, 12, Bios 01, 02, 05, 06, 07, 12, 13, 14, 17, } \\
\text { GNDVI, NDVI, RVI, TVI }\end{array}$ & 28 \\
\hline
\end{tabular}

the DEM was used to derive the Topographic Wetness Index (TWI), slope, aspect elevation and Topographic Position Index (TPI). These topographic indices have been demonstrated in the literature as having significant influence on vegetation growth patterns and distribution as they influence the net radiation and soil moisture distribution and availability (Shoko et al., 2019). Before modelling, the DEM was preprocessed to eliminate imperfections associated with the data. DEM pre-processing was conducted in a GIS environment, using the spatial analyst extension tool. The DEM-based surface terrain variables, i.e. elevation, aspect and slope, were extracted using the surface extension spatial analyst tool. On the other hand, the TWI, which is a hydrological index that determines the variability in soil water conditions, was derived using the hydrological spatial analyst (Shoko et al., 2019). The DEM-derived L. camara model input parameters were standardized to the same resolution as that of remotely sensed derived vegetation indices, using nearest neighbour resampling technique in a GIS environment. Resampling of the DEM variables and remotely sensed variables was meant to ensure their compatibility and consistency in mapping and modelling of $L$. camara.

\subsection{Vegetation indices}

Sentinel-2 data were used to generate four vegetation indices, namely Normalized Difference Vegetation Index (NDVI) (Rouse et al., 1973), Transformed Vegetation Index (TVI) (Deering, 1975), Ratio Vegetation Index (RVI) (Baret \& Guyot, 1991) and Green Normalized Difference Vegetation Index (GNDVI) (Gitelson \& Merzlyak, 1998). The NDVI was derived using the red and near-infrared bands to evaluate changes in the phenology of vegetation, which therefore uses the utmost absorption and reflection, and reflectance of the chlorophyll. Additionally, the TVI is used in the elimination of negative values as well as the transformation of NDVI histograms to an ordinary distribution (Deering, 1975; Mróz \& Sobieraj, 2004). The RVI is based on the principle that leaves absorb more red wavelengths than infrared light. The RVI is sensitive to vegetation and have a significant relationship with plant biomass; as such, it is mostly used for estimating and monitoring vegetation (green) biomass (Xue \& Su, 2017). The GNDVI is an index of plant and one of the most generally utilized indices to assess canopy variation in biomass (Gitelson \& Merzlyak, 1998). The selected spectral indices were informed by their performance in vegetation mapping as reported in the literature (Dube et al., 2014, 2018; Shoko et al., 2018).

\section{5 | Bioclimatic data}

Current climate data layers generated through the interpolation of average monthly data using the splining techniques were obtained. Bioclimatic variables were derived as raster grid format of a 30 arc-seconds spatial resolution from the current WorldClim climatic conditions database (http://www.worldclime.org/). The bioclimatic variables used in this study were derived from the monthly temperature and rainfall data to produce variables that are biologically relevant. These climatic datasets are an average of long-term measurements (30 years of data) and contain grids of rainfall, temperature and derived bioclimatic summary variables (Hijmans et al., 2005). The variables were categorized into temperature and soil moisture. As such, all other variables were resampled to a $30 \mathrm{~m}$ spatial resolution and projected to the Universal Transverse Mercator (UTM). This was meant to enhance compatibility with topographic variables. To ensure that all variables match, the variables were converted from raster format to American Standard Code for Information Interchange (ASCII) to ensure their compatibility with the Maxent algorithm for easy implementation (Jarnevich \& Reynolds, 2011).

\section{6 | Modelling L. camara distribution}

Freely available maximum entropy (Maxent) model was downloaded from (http://biodiversityinformatics.amnh.org/open_sourc e/maxent/). The remaining model parameters were set to default replication of one, with 500 iterations, using cross-validation. The advantage of Maxent is that it has the ability to use presenceonly data incorporated with interactions amongst categorical and continuous data (Ficetola et al., 2007). Furthermore, the Maxent algorithm is developed to improve on detection of the probability 
distribution; hence, the method is less likely to be influenced by the number and spatial error of sample size (Hernandez et al., 2006). To reduce model overfitting, regularization multipliers were set to four (Ndlovu et al., 2018). The clog-log output format was used due to its ability to predict the area of moderately high invasion when compared to the logistic output (Kumbula et al., 2019). During the model training, the Maxent entropy algorithm also performs a jackknife test, which is key in assessing the relative importance of predictor variables that explain the spatial distribution of the species, including the unique information provided by each variable (Phillips \& Dudík, 2008). This method was thus used to analyse the effects of environmental variables on model results to indicate influential variables as it can estimate parameters and adjust the deviation without assumptions of distribution probability (Kumbula et al., 2019). A summary of different modelling scenarios adopted in this study is detailed in Table 1.

\section{7 | Model evaluation}

To evaluate the models performance and accuracy, the AUC, which is a threshold-independent measure of accuracy, the TSS and Cohen's Kappa, which are threshold-dependent measures of accuracy, were used. The AUC tests the agreement between the observed species presence and the estimated distribution, indicating whether the classifier (Phillips et al., 2006) correctly ordered the probability of presence (sensitivity) versus absence (specificity). An AUC value of 0.5 shows that model predictions are not better than random; <0.5 worse than random; 0.5-0.7 poor performance; 0.70.9 reasonable/moderate performance; and $>0.9$ high performance (West et al., 2016). Kappa has been used to measure the model performance. However, it has been highly criticized for dependence on prevalence (Allouche et al., 2006). As such, the TSS has been presented as an alternative measure of accuracy as it corrects this dependence while retaining the advantages of Kappa. Furthermore,

TABLE 2 Evaluation results for all model scenarios

\begin{tabular}{|llll|}
\hline Model scenarios & AUC & TSS & KAPPA \\
\hline Model 1 & 0.924 & 0.667 & 0.338 \\
\hline Model 2 & 0.906 & 0.621 & 0.328 \\
\hline Model 3 & 0.925 & 0.751 & 0.397 \\
\hline Model 4 & 0.854 & 0.549 & 0.295 \\
\hline Model 5 & 0.952 & 0.773 & 0.401 \\
\hline Model 6 & 0.928 & 0.698 & 0.367 \\
\hline Model 7 & 0.955 & 0.765 & 0.387 \\
\hline
\end{tabular}

(a)

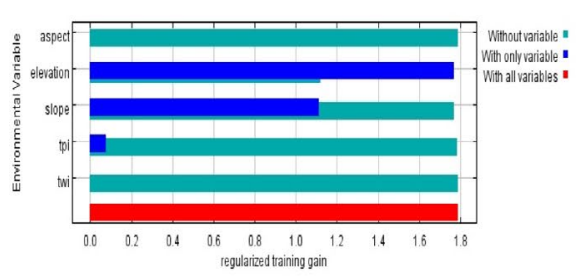

(d)

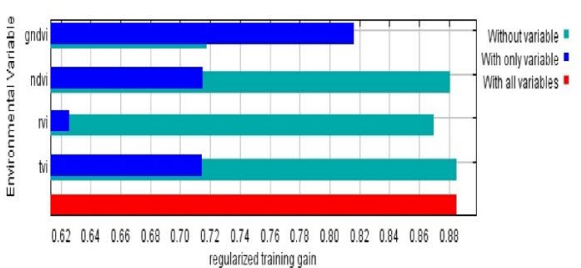

(g)



(b)
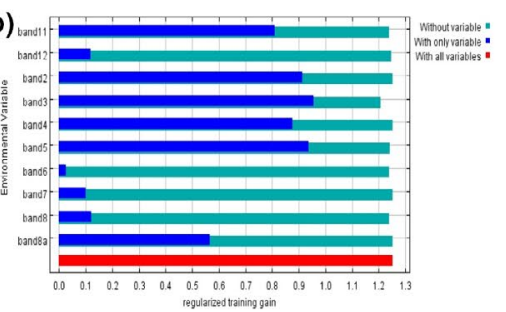

(c)



(e)
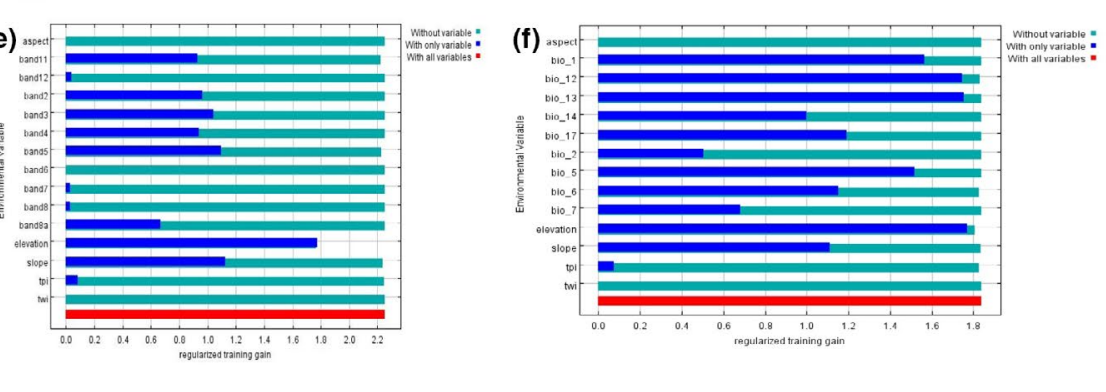

FIGURE 2 Jackknife test of variable importance (a) topographic variables, (b) sentinel bands, (c) bioclimatic variables, (d) selected vegetation indices, (e) topographic variables and sentinel bands, (f) topographic and bioclimatic variables, (g) composite of all variables 

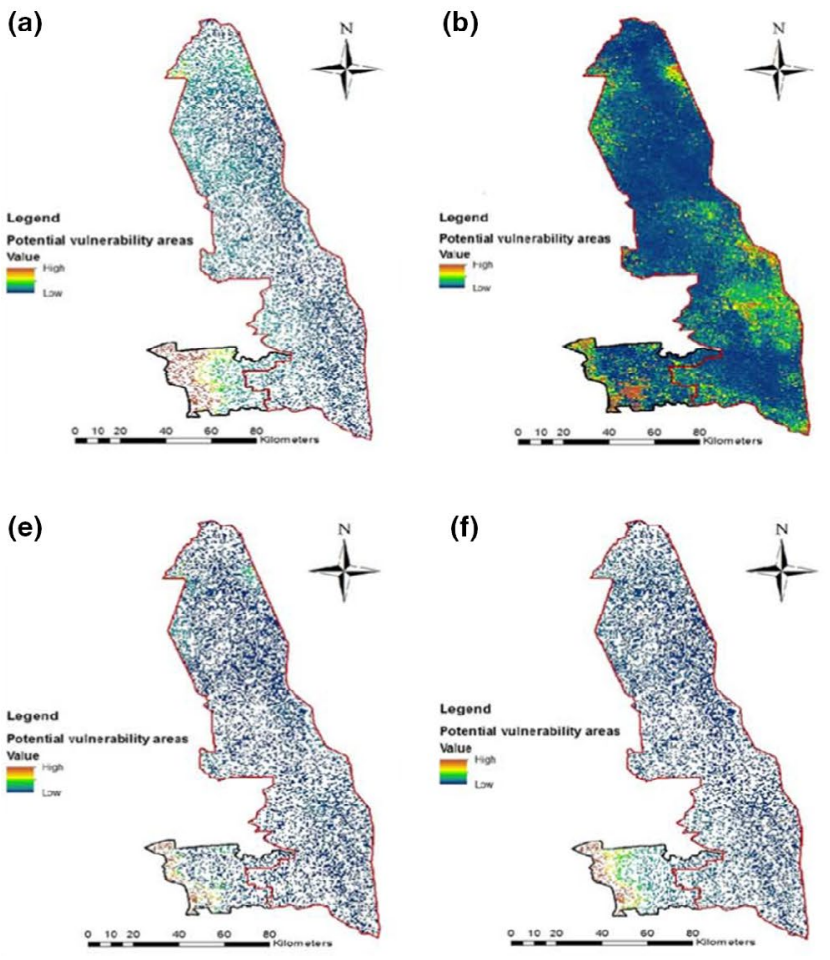
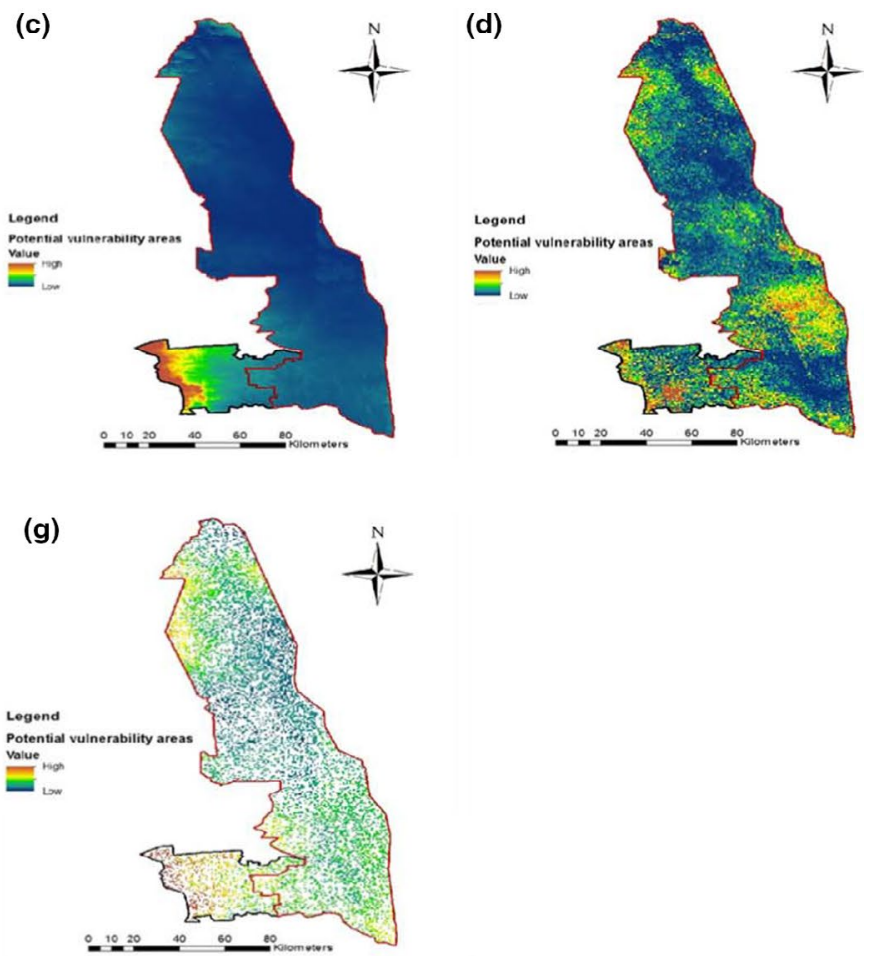

FIGURE 3 Spatial distribution of Lantana camara as predicted by Maxent where the following variables were used for each model: (a) topographic variables, (b) sentinel bands, (c) bioclimatic variables, (d) selected vegetation indices, (e) topographic variables and sentinel bands, (f) topographic and bioclimatic variables, $(\mathrm{g})$ composite of all variables

the error matrix was used to derive specificity, sensitivity, Kappa and TSS values using background samples as absence data. The 10-percentile threshold value was used to evaluate classification accuracy.

\section{$3 \mid$ RESULTS}

\section{1 | Model accuracy}

The results in Table 2 show the derived AUC, TSS and Kappa values. The model that used all variables achieved the highest predictive accuracies and had the highest performance, attaining an AUC of 0.96 , a TSS of 0.77 and a Kappa of 0.39. On the other hand, the model developed based on indices alone achieved the lowest accuracies, yielding an AUC of 0.854, a TSS of 0.549 and a Kappa 0.30.

The results in Figure 2 show the jackknife test of variable importance. The findings ranked elevation as the overall most influential variable in predicting areas most vulnerable to the invasion of $L$. $c a$ mara. As observed in Models 1 (a), 5 (e), 6 (f) and 7(g), elevation is the environmental variable with the highest gain, when it is used in isolation, and it therefore, appears to have the most useful information on the spread of L. camara. Furthermore, it is also the only environmental variable with the highest mean decrease in accuracy omitted from the model. The use of Models 3 (c) and 4 (d) depicted bio 12 (mean annual rainfall) and GNDVI as standalone yielded the highest gain and leads to poor model performance omitted, whereas
Model 7 (g) depicted band 5 (vegetation red edge) as the most important variable.

\subsection{Spatial distribution of L. camara}

The integration of multi-source data (environmental and remotely sensed variables) successfully predicted the spatial distribution of L. camara in both the protected and unprotected areas. Figure 3a-g shows the predicted potential habitats suitable for L. camara occurrence. The warm colours illustrate high level of invasion while cooler colours illustrate low level of invasion. The results from all the predictive models indicated that invasion is more likely to occur in the communal area of the study area that is Bushbuckridge, specifically in moisty areas. Although invasion is taking place in the protected area, the level of invasion is lower. For example, Figure 3a, c, e, f shows that $L$. camara invasion is more pronounced in the communal lands of Bushbuckridge when compared to the protected area. However, the results in Figure 3a and d demonstrate that the protected area (Kruger National Park) has isolated patches of invasion by $L$. camara occurrence with great occurrence noted in the northern part of the park and central parts. Further, dry areas within the protected area have low levels of invasion while the areas that have moister have some invasion taking place, specifically the central eastern part of the protected area. Overall, the distribution maps seem to be in agreement with the areas that are most vulnerable to the invasion of L. camara. 


\section{3 | Discussion}

The study modelled the potential spatial distribution of L. camara in savannah ecosystems, using the Maxent entropy model. Results revealed that Bushbuckridge communal lands are more vulnerable to the invasion by L. camara when compared to the Kruger National Park. Similar trends have been observed in other studies; for example, Rodgers and Parker (2003) compared two tourist islands (the St. Simons Island and Jekyll Island) and two protected National Wildlife Refuge Islands (the Blackbeard Island and Wassaw Island) to find the island that is the most highly invaded by alien plants. It was found that Alien plant cover was greater in severely disturbed sites than in less disturbed sites on all islands and in both habitats. This is further supported by the work by Lin (2007) who observed that major roadsides of Moorea, French Polynesia, were infested with L. camara. It was found that the roadside area covered by L. camara was $1.99 \%$ whereby the presence was correlated with the roadside habitat type with the highest being in areas of agricultural disturbance. The area covered by L. camara was also positively correlated with soil moisture and slope. According to Sharma et al. (2005), disturbed areas such as railway tracks, roadsides and canals are more favourable for the species distribution. This is because the occurrence and spread of IAPs are influenced by the presence of optimal growth conditions and the altered disturbance regimes that are caused by anthropogenic activities increase the performance of the invading species over that of native species (Daehler, 2003). As a result, IAPs are usually invading disturbed areas (Hobbs \& Huenneke, 1992). These disturbance decreases the cover and the vigour of competitors, and it increases the resource levels, which, in turn, facilitate invasions (Kneitel \& Perrault, 2006).

Results further indicated that some variables highly influence the spatial distribution of L. camara while others have no significant contribution. The model developed using all variables yielded the highest predictive accuracies and had the highest performance. The literature reported similar observations when models developed with a composite of various variables performed better than those based exclusively on one set of variables (Buermann et al., 2008; Parra et al., 2004; Parviainen et al., 2013; Saatchi et al., 2008). Furthermore, all the models achieved AUC values of above $>0.85$. These results are consistent with those of Phillips and Dudík (2008) and therefore indicate that the models were able to predict areas vulnerable to L. camara invasion.

In addition, the findings of this study have indicated that the elevation was the only environmental variable with the highest gain, when used as independent model dataset in modelling the distribution of L. camara. Our results are in line with those of Ndlovu et al. (2018) and Adeola (2017) whose work demonstrated that elevation explained probability of occurrence $(p>0.5)$. According to Adeola (2017), elevation is a variable that has an influence on the spatial distribution of plant species as well as soil properties. This is supported by the findings of Priyanka and Joshi $(2013 a, b)$ who observed the superiority of elevation gradients in accordance with the expected species since L. camara flourishes well at lower altitudinal ranges, and as it increases, the species occurrence tends to diminish.
Furthermore, Band 5 (vegetation red edge) derived from Sentinel-2 was depicted as another variable that is important in modelling invasive L. camara. According to Delegido et al. (2011), the inclusion of Sentinel-2 red edge bands is important in enabling the detection of subtle green canopy and chlorophyll content. The red edge is important for the prediction of L. camara as the sensitivity of its presence to the red-edge bands is in line with the assertion that subtle vegetation changes and characteristics or variations are prominent in some portions of the electromagnetic spectrum (Zhu et al., 2007). Hence, its attributes can be probabilistically determined in terms of the red-edge band reflectance. Vegetation red edge bands contribute to vegetation mapping and offer broader discrimination. Dhau et al. (2017) have stressed the potential of vegetation red edge in vegetation mapping and prediction.

\section{4 | Conclusions}

The findings of this work demonstrate that communal areas of Bushbuckridge are more likely to be invaded by L. camara when compared to the Kruger National Park. Almost $10 \%$ of the communal area is more likely to be invaded by L. camara, whereas only $7 \%$ of the Kruger National Park is anticipated to be invaded. Furthermore, findings of this study revealed that the Maxent-based models performed exceptionally well with AUC scores $>0.85$. The model developed using all the variables yielded the highest predictive accuracies and had the highest performance. In addition, the results demonstrated that elevation plays a critical role in the spatial distribution of $L$. camara when compared to other variables considered in this study. The findings of this study could assist in conservation planning and management of invasive species and protected areas. Moreover, such information is vital for ecologists, land managers and policy-makers in the monitoring of areas that are vulnerable to the invasion of $L$. camara and where early response mechanisms could be put in place.

\section{CONFLICT OF INTEREST}

Authors would like to declare no conflict of interest.

\section{DATA AVAILABILITY STATEMENT}

The data that support the findings of this study are available from the corresponding author upon request.

\section{ORCID}

Timothy Dube (D) https://orcid.org/0000-0003-3456-8991

Xivutiso Glenny Maluleke (D) https://orcid.

org/0000-0002-0444-646X

\section{REFERENCES}

Addabbo, P., Focareta, M., Marcuccio, S., Votto, C., \& Ullo, S. L. (2016). Contribution of sentinel-2 data for applications in vegetation monitoring. ACTA IMEKO, 5(2), 44. https://doi.org/10.21014/acta_ imeko.v5i2.352

Adeola, A. M. (2017). Modelling susceptibility to Parthenium hysterophorus invasion in KwaZuluNatal Province, South Africa using physical, climatic and remotely sensed derived variables. Unpublished MSc 
Thesis, School of Agricultural, Earth and Environmental Sciences, University of KwaZulu-Natal. Pietermaritzburg, RSA.

Allouche, O., Tsoar, A., \& Kadmon, R. (2006). Assessing the accuracy of species distribution models: Prevalence, kappa and the true skill statistic (TSS). Journal of Applied Ecology, 43(6), 1223-1232.

Baret, F., \& Guyot, G. (1991). Potentials and limits of vegetation indices for LAI and APAR assessment. Remote Sensing of Environment, 35(23), 161-173.

Bateman, B. L., Van Der Wal, L., \& Johnson, C. N. (2012). Nice weather for bettongs: Using weather events, not climate means, in species distribution models. Ecography, 35, 306-314.

Beaumont, L. J., Hughes, L., \& Pitman, A. J. (2008). Why is the choice of future climate scenarios for species distribution modelling important? Ecology Letters, 11, 1135-1146. https://doi. org/10.1111/j.1461-0248.2008.01231.x

Buermann, W., Saatchi, S., Smith, T. B., Zutta, B. R., Chaves, J. A., Milá, B., \& Graham, C. H. (2008). Predicting species distributions across the Amazonian and Andean regions using remote sensing data. Journal of Biogeography, 35(7), 1160-1176.

Daehler, C. C. (2003). Performance comparisons of co-occurring native and alien invasive plants: Implications for conservation and restoration. Annual Review of Ecology, Evolution, and Systematics, 34, 183-211. https://doi.org/10.1146/annurev.ecols ys.34.011802.132403

Deering, D. (1975). Measuring" forage production" of grazing units from Landsat MSS data. Paper presented at the Proceedings of the Tenth International Symposium of Remote Sensing of the Environment.

DeFries, R. S., Asner, G. P., \& Houghton, R. (2004). Trade-offs in land-use decisions: Towards a framework for assessing multiple ecosystem responses to land-use change. Ecosystem Land Use Change, 2, 1-9.

Delegido, J., Verrelst, J., Alonso, L., \& Moreno, J. (2011). Evaluation of sentinel-2 red-edge bands for empirical estimation of green LAl and chlorophyll content. Sensors, 11, 7063-7081.

Dhau, I. (2008). A spatio-temporal analysis of Lantana camara across contrasting land tenure regimes in Zimbabwe. ITC.

Dhau, I., Adam, E., Mutanga, O., Ayisi, K., Abdel-Rahman, E. M., Odindi, J., \& Masocha, M. (2017). Testing the capability of spectral resolution of the new multispectral sensors on detecting the severity of grey leaf spot disease in maize crop. Geocarto International, 33(11), 1223-1236. https://doi.org/10.1080/10106049.2017.1343391

Dobhal, P. K., Kohli, R. K., \& Batish, D. R. (2011). Impact of L. camara L. Invasion on riparian vegetation of Nayar region in Garhwal Himalayas (Uttarakhand, India). Journal of Ecology and the Natural Environment, 3(1), 11-22.

Dube, T., Muchena, R., Masocha, M., \& Shoko, C. (2018). Estimating soil organic and aboveground woody carbon stock in a protected dry Miombo ecosystem, Zimbabwe: Landsat 8 OLI data applications. Physics and Chemistry of the Earth, 105, 154-160. https://doi. org/10.1016/j.pce.2018.03.007

Dube, T., \& Mutanga, O. (2015). Quantifying the variability and allocation patterns of aboveground carbon stocks across plantation forest types, structural attributes and age in sub-tropical coastal region of KwaZulu Natal, South Africa using remote sensing. Journal of Applied Geography, 64, 55-65.

Dube, T., Mutanga, O., Elhadi, A., \& Ismail, R. (2014). Intra-and-inter species biomass prediction in a plantation forest: Testing the utility of high spatial resolution spaceborne multispectral Rapideye sensor and advanced machine learning algorithms. Sensors, 14(8), 1534815370. https://doi.org/10.3390/s140815348

Dube, T., Mutanga, O., \& Ismail, R. (2016). Quantifying aboveground biomass in African environments: A review of the trade-offs between sensor estimation accuracy and costs. Tropical Ecology, 57(3), 393-405.

Fernando, G. M. T. S., Nalaka, K., Suraweera, P., \& Kumari, B. (2016). Identification of Distribution of Lantana camera (Exotic Invasive
Species) and its impacts on Udawalawa National Park. Sri Lanka, 214-254.

Ficetola, G. F., Thuiller, W., \& Miaud, C. (2007). Prediction and validation of the potential global distribution of a problematic alien invasive species-the American bullfrog. Diversity and Distributions, 13(4), 476-485.

Gallien, L., Douzet, R., Pratte, S., Zimmermann, N. E., \& Thuiller, W. (2012). Invasive species distribution models - how violating the equilibrium assumption can create new insights. Global Ecology and Biogeography, 21, 1126-1136.

Gitelson, A. A., \& Merzlyak, M. N. (1998). Remote sensing of chlorophyll concentration in higher plant leaves. Advances in Space Research, 22(5), 689-692.

Gooden, B., French, K. O., \& Turner, P. (2009). Invasion and management of a woody plant, L. camara L., alters vegetation diversity within wet sclerophyll forest in southeastern Australia. Forest Ecology \& Management, 257(3), 960-967.

Guisan, A., \& Thuiller, W. (2005). Predicting species distribution: Offering more that simple habitat models. Ecology Letters, 8, 993-1009.

Hernandez, P. A., Graham, C. H., Master, L. L., \& Albert, D. L. (2006). The effect of sample size and species characteristics on performance of different species distribution modelling methods. Ecography, 29, 773-785.

Hijmans, R. J., Cameron, S. E., Parra, J. L., Jones, P. G., \& Jarvis, A. (2005). Very high resolution interpolated climate surfaces for global land areas. International Journal of Climatology, 25(15), 1965-1978.

Hobbs, R. J., \& Huenneke, L. F. (1992). Disturbance, diversity, and invasion: Implications for conservations. Conservation Biology, 6(3), 324-337. https://doi.org/10.1046/j.1523-1739.1992.06030324.x

Huang, C., \& Gregory, P. A. (2009). Applications of remote sensing to alien invasive plant studies. Sensors, 9, 4869-4889.

Jarnevich, C. S., \& Reynolds, L. V. (2011). Challenges of predicting the potential distribution of a slow-spreading invader: A habitat suitability map for an invasive riparian tree. Biological Invasions, 13, 153-163. https://doi.org/10.1007/s10530-010-9798-4

Kimothi, M. M., \& Dasari, A. (2010). Methodology to map the spread of an invasive plant (Lantana camara L.) in forest ecosystems using Indian remote sensing satellite data. Int J Remote Sens, 31(12), 3273-3289.

Kneitel, J. M., \& Perrault, D. (2006). Disturbance-induced changes in community composition increase species invasion success. Community Ecol, 7(2), 245-252.

Kozak, K. H., Graham, C. H., \& Wiens, J. J. (2008). Integrating GIS-based environmental data into evolutionary biology. Trends in Ecology \& Evolution, 23(3), 141-148.

Kumbula, S. T., Mafongoya, P., Peerbhay, K. Y., Lottering, R. T., \& Ismail, R. (2019). Using sentinel-2 multispectral images to map the occurrence of the cossid moth (Coryphodema tristis) in Eucalyptus nitens plantations of mpumalanga, South Africa. Remote Sensing, 11, 278. https://doi.org/10.3390/rs11030278

Lin, S. (2007). The distribution and role of an invasive plant species, L. camara, in disturbed roadside habitats in Moorea, French Polynesia.

Mack, R. N., Simberloff, D., Londsdale, W. M., Evans, H., Clout, M., \& Bazzaz, F. A. (2000). Biotic invasions: Causes, epidemiology, global consequences, and control. Ecological Applications, 10, 689-710. https://doi. org/10.1890/1051-0761(2000)010\%5B0689:BICEGC\%5D2.0.CO;2

Masocha, M., Dube, T., Skidmore, A., Holmgren, M., \& Prins, H. (2017). Assessing effect of rainfall on rate of alien shrub expansion in a southern African savanna. African Journal of Range \& Forage Science, 34(1), 39-44. https://doi.org/10.2989/10220119.2017.1311943

Merow, C., Bois, S. T., Allen, J. M., Xie, Y., \& Silander, J. A. (2017). Climate change both facilitates and inhibits invasive plant ranges in New England. Proceedings of the National Academy of Sciences, 114, 3276-3284. https://doi.org/10.1073/pnas.1609633114

Mróz, M., \& Sobieraj, A. (2004). Comparison of several vegetation indices calculated on the basis of a seasonal SPOT XS time series, and 
their suitability for land cover and agricultural crop identification Technical Sciences, 7(7), 39-66.

Mullerova, J., Pergl, J., \& Pysek, P. (2013). Remote sensing as a tool for monitoring plant invasions: testing the effects of data resolution and image classification approach on the detection of a model plant species Heracleum mantegazzianum (giant hogweed). International Journal of Applied Earth Observation and Geo-information, 25, 55-65. https://doi.org/10.1016/j.jag.2013.03.004

Ndlovu, P., Mutanga, O., Sibanda, M., Odindi, J., \& Rushworth, I. (2018). Modelling potential distribution of bramble (rubus cuneifolius) using topographic, bioclimatic and remotely sensed data in the KwaZulu-Natal Drakensberg, South Africa. Applied Geography, 99, 54-62. https://doi.org/10.1016/j.apgeog.2018.07.025

Odindi, J., Adam, E., Ngubane, Z., Mutanga, O., \& Slotow, R. (2014). Comparison between WorldView-2 and SPOT-5 images in mapping the bracken fern using the random forest algorithm. Journal of Applied Remote Sensing, 8, 083527. https://doi.org/10.1117/1. JRS.8.083527

Parra, J. L., Graham, C. C., \& Freile, J. F. (2004). Evaluating alternative data sets for ecological niche models of birds in the Andes. Ecography, 27(3), 350-360.

Parviainen, M., Zimmermann, N. E., Heikkinen, R. K., \& Luoto, M. (2013). Using unclassified continuous remote sensing data to improve distribution models of red-listed plant species. Biodiversity and Conservation, 22(8), 1731-1754.

Pearson, R. G., Dawson, T. P., \& Liu, C. (2004). Modelling species distributions in Britain: A hierarchical integration of climate and land-cover data. Ecography, 27(3), 285-298. https://doi. org/10.1111/j.0906-7590.2004.03740.x

Phillips, S. J., Anderson, R. P., \& Schapire, R. E. (2006). Maximum entropy modeling of species geographic distributions. Ecological Modelling, 190(3), 231-259.

Phillips, S. J., \& Dudík, M. (2008). Modeling of species distributions with Maxent: New extensions and a comprehensive evaluation. Ecography, 31(2), 161-175.

Priyanka, N., \& Joshi, P. K. (2013). Modeling spatial distribution of L. camara - A comparative study. Canadian Journal of Basic and Applied Science, 01, 100-117.

Priyanka, N., \& Joshi, P. K. (2013). A review of L. camara studies in India International. Journal of Scientific and Research Publications, 3 , 2250-3153.

Rocchini, D., Andreo, V., Förster, M., Garzon-Lopez, C. X., Gutierrez, A. P., Gillespie, T. W., Hauffe, H. C., He, K. S., Kleinschmit, B., \& Mairota, P. (2015). Potential of remote sensing to predict species invasions: A modelling perspective. Progress in Physical Geography, 39(3), 283-309.

Rodgers, J. C. III, \& Parker, K. C. (2003). Distribution of alien plant species in relation to human disturbance on the Georgia Sea Islands. Diversity and Distributions, 9, 385-398. https://doi. org/10.1046/j.1472-4642.2003.00036.x

Rouse, J. W. Jr, Haas, R. H., Schell, J. A., \& Deering, D. W. (1973). Monitoring vegetation systems in the Great Plains with ERTS In S. C. Freden, E. P. Mercanti, \& M. Becker (Eds.), Third earth resources technology satellite-1 symposium (pp. 309-317). Technical Presentations, Section A, I.

Saatchi, S., Buermann, W., Ter Steege, H., Mori, S., \& Smith, T. B. (2008). Modeling distribution of Amazonian tree species and diversity using remote sensing measurements. Remote Sensing of Environment, 112(5), 2000-2017.

Sharma, G. P., Raghubanshi, A. S., \& Singh, J. S. (2005). Lantana invasion: An overview. Weed Biology and Management, 5, 157-165. https:// doi.org/10.1111/j.1445-6664.2005.00178.x

Shoko, C., Mutanga, O., \& Dube, T. (2018). Determining optimal new generation satellite derived metrics for accurate $\mathrm{C} 3$ and $\mathrm{C} 4$ grass species aboveground biomass estimation in South Africa. Remote Sensing, 10(4), 564. https://doi.org/10.3390/rs10040564

Shoko, C., Mutanga, O., \& Dube, T. (2019). Remotely sensed C3 and C4 grass species aboveground biomass variability in response to seasonal climate and topography. African Journal of Ecology, 57(4), 477489. https://doi.org/10.1111/aje.12622

Sibanda, M., Mutanga, O., \& Rouget, M. (2015). Examining the potential of Sentinel-2 MSI spectral resolution in quantifying above ground biomass across different fertilizer treatments. ISPRS Journal of Photogrammetry and Remote Sensing, 110, 55-65.

Taylor, S., \& Kumar, L. (2014). Impacts of climate change on invasive L. camara L. distribution in South Africa. African Journal of Environmental Science and Technology, 8(6), 391-400.

Taylor, S., Kumar, L., \& Reid, N. (2011). Accuracy comparison of Quickbird, Landsat TM and SPOT 5 imagery for L. camara mapping. Journal of Spatial Science, 56(2), 241-252.

Thamaga, K. H., \& Dube, T. (2018). Remote sensing of invasive water hyacinth (Eichhornia crassipes): A review on applications and challenges. Remote Sensing Applications: Society and Environment, 10, 36-46. https://doi.org/10.1016/j.rsase.2018.02.005

Thamaga, K. H., \& Dube, T. (2018). Testing two methods for mapping water hyacinth (Eichhornia crassipes) in the Greater Letaba river system, South Africa: discrimination and mapping potential of the polar-orbiting Sentinel-2 MSI and Landsat $8 \mathrm{OLI}$ sensors. International Journal of Remote Sensing, 39(22), 8041-8059.

Vardien, W., Richardson, D. M., Foxcroft, L. C., Thompson, G. D., Wilson, J. R. U., \& Le Roux, J. J. (2012). Invasion dynamics of L. camara L. (sensu lato) in South Africa. South African Journal of Botany, 81, 81-94.

Wang, A., Goslee, S. C., Miller, D. A., Sanderson, M. A., \& Gonet, J. M. (2017). Topographic variables improve climaticmodels of forage species abundance in the northeastern United States. Applied Vegetation Science, 20, 84-93. https://doi.org/10.1111/avsc.12284

West, A. M., Kumar, S., Brown, C. S., Thomas, J., \& Bromberg, S. J. (2016). Field validation of an invasive species Maxent model. Ecological Informatics, 36, 126-134.

Wisz, M. S., Hijmans, R. J., Li, J., Peterson, A. T., Graham, C. H., \& Guisan, A. (2008). Effects of sample size on the performance of species distribution models. Diversity and Distributions, (Diversity Distrib.), 14, 763-773. https://doi.org/10.1111/j.1472-4642.2008.00482.x

Xie, Y., Sha, Z., \& Yu, M. (2008). Remote sensing imagery in vegetation mapping: A review. Journal of Plant Ecology, 1(1), 9-23. https://doi. org/10.1093/jpe/rtm005

Xue, J., \& Su, B. (2017). Significant remote sensing vegetation indices: A review of developments and applications. Journal of Sensors, 1-17, 1353691. https://doi.org/10.1155/2017/1353691

Zhang, J., \& Foody, G. M. (1998). A fuzzy classification of sub-urban land cover from remotely sensed imagery. International Journal of Remote Sensing, 19, 2721-2738. https://doi.org/10.1080/01431 1698214479

Zhu, L. I., Osbert, J. S., Weiguo, S., Zhenyu, L. I., \& Keping, M. (2007). Predicting the spatial distribution of an invasive plant species (Eupatorium adenophorum) in China. Landscape Ecology, 22, 11431154. https://doi.org/10.1007/s10980-007-9096-4

How to cite this article: Dube, T., Maluleke, X. G., \& Mutanga, O. (2022). Mapping rangeland ecosystems vulnerablility to Lantana camara invasion in semi-arid savannahs in South Africa. African Journal of Ecology, 00, 1-10. https://doi. org/10.1111/aje.12951 